tasks. If we have learned anything it is that only the fine detail of a patient's performance suffices for model building, and that, at this level, theoretically important individual variation is paramount. Shallice does not dismiss all group studies in neuropsychology, but he does give good guidelines concerning their restricted use. In the course of so doing he also attacks one of the sacred methodological cows of the ultra-cognitivists. It is not the case, Shallice argues, that a double-dissociation between two patients' performance on two tasks always implies the existence of two distinct processing modules.
I have touched on only a small sample of the topics that Shallice considers, and should accordingly note that he discusses in depth most of the salient conceptual issues and controversies in the field. Neuropsychologists and behavioural neurologists will need to study this book with pencil in hand and work through the structure of each argument. Man is by nature lazy and inclined to data-collection for its own sake, but the practice of thinking may cure these faults.

John C. Marshall is in the Neuropsychology Unit, part of the Neuroscience Group at the Radcliffe Infirmary, Oxford OX2 6HE, UK.

\section{Language of life}

\section{Jonathan Howard}

Macmillan Dictionary of Immunology By Fred S. Rosen, Lisa A. Stèiner and Emil R. Unanue. Macmillan, London/Stockton, New York: 1989. Pp.223. Hbk £25, $\$ 50$; pbk £9.95, \$20.

PERHAPS nineteen eighty nine will be remembered as the year when the new edition of The Oxford English Dictionary was published. Certainly, anybody obliged by tradition or poverty to put up with any previous Oxford dictionary was living in a lexical world so antiquated as to be disabling for contemporary life.

But $£ 1,500$ is a lot to pay for a work that still lacks most of the entries in Rosen, Steiner and Unanue's Macmillan Dictionary of Immunology. My mother, one of many people who sent material for the new $O E D$, contributed a quarter of a million items, but none of them was immunological. And this despite repeated attempts to convince her that even immunology's ugliest coinage was as worthy as the words she mined from the "trash" (as The Guardian's dictionary critic put it a few weeks ago) that she so much liked to read. Well, that's the $O E D$ for you. Apparently it was a matter of policy not to attempt to grow with scientific language; too much, too fast. Possibly, did they hope, too ephemeral? But scientific language, like the rest of language, is here to be understood and used, and then to pass gracefully into history when its usefulness has been exhausted. And to my mind, at least, it would be sad if there were no record of its passing.

Rosen, Steiner and Unanue's dictionary is excellent. The three authors are immunologists of unimpeachable distinction in a suitably complementary collection of fields (clinical immunology, immunochemistry and cellular immunology). They have done a fine job of covering the whole field, and most impressively of all, have managed to keep the whole thing so up to date that it is actually useful.
One of the more attractive aspects of the definitions is the insistence that much is not yet known. The importance of genetic manipulation techniques to immunology is reflected in entries such as 'cosmid', 'Cot' and 'nick translation'. So much so, perhaps, that 'germinal centre', 'medial histocompatibility antigen' and 'high endothelial venule', all three more distinctively immunological, one would have supposed, appear to have been squeezed out. But if an entry is there, and it often is, it is correct, succinct and right up to the minute. And if HEVs did not make it, the recirculators amongst us will be glad to see that MEL14 is there. Rosen's contribution is perhaps the most distinctive: I see his hand in the quite extraordinary collection of immunological disorders our species is subject to, which litter every page.

Scientists are incorrigible wordsmiths, perhaps in part because to name something confers title, though there are, of course, other more laudable motives. Nowadays, it's a free-for-all. New words teem into the world, willy-nilly born, but not by any means all divinely formed. It was not always so. Michael Faraday consulted the greatest wordsmith of all, the man who gave us 'scientist', when he needed terms to deal with the torrent of new ideas generated by the discovery of the electrolytic decomposition of aqueous solutions. So William Whewell sat down and created 'ions', 'electrodes', 'anodes', 'cathodes' - a whole vocabulary. But who will do for us now what Whewell did for Faraday? 'Cosmid' is a lovely word, 'genome' too; and so are some of the transferred usages such as 'library'. But where was Whewell when 'agretope', 'desetope', 'histotope' and 'restitope', all dutifully defined by our poor authors, first wrinkled our brows? When this dictionary moves into its next edition, I sincerely hope that these immunological oddities will have passed, like 'oecotaxis', into immunolexicographical history.

Jonathan Howard is in the Department of Immunology, Institute of Animal Physiology and Genetics, Babraham, Cambridge CB2 4AT, UK.

\section{Rocking in the laboratory}

\author{
Gordon M. Biggar
}

Simulating the Earth: Experimental Geochemistry. By J. R. Holloway and B. J. Wood. Unwin Hyman: 1988. Pp.196. Hbk £25, \$39.95; pbk £11.95, \$19.95.

ENCOURAGING the more traditionally trained geological graduates (or undergraduates) to expand their horizons into experimental geology has never been easy. Now, however, in Simulating the Earth we have an enjoyable account of some of the best experimental work that has been done, set out with simple instructional diagrams and sketches, and giving all the essentials, all the encouragement that one could hope for.

Each example tells the story of what the experimenter was trying to achieve and how well he succeeded. Thereby another brick is added to the edifice of geological (physical and chemical) prediction, leaving readers with an understanding of many geological processes which they may have seen in their rocks, sometimes without realizing that they were accessible to experimental verification. If students or researchers are sufficiently inspired to turn their hands to practicalities, there are many well-equipped experimental laboratories around the world which welcome working visitors. Those visitors can now commence their experiments well informed of what they might achieve and how.

For all its modest cost, Simulating the Earth is two books in one - a practical guide to the equipment in the early chapters and the appendices, and a comprehensive intellectual guide, often through the examples provided, to the whys and wherefores. Many fields are covered: there is something for everybody, no matter whether 'everybody' is interested in metamorphic rocks, thermodynamics, fluid phases, speciation of ions in fluids and liquids, volatilization, spectroscopy, igneous rocks, element partitioning, differentiation viscosity or many other topics. Nor will established workers in experimental geology be disappointed (the book is subtitled Experimental Geochemistry, but moves in Chapter 9 into measurements of physical properties). They will find a concise resumé of what they thought they knew, and some hidden gems of information or philosophy to widen appreciation of their speciality. "Putting it all together", to quote from Chapter 4, is what Holloway and Wood have succeeded in doing, and this phrase summarizes the whole book.

Gordon M. Biggar is in the Grant Institute of Geology, University of Edinburgh, West Mains Road, Edinburgh EH9 3JW, UK. 